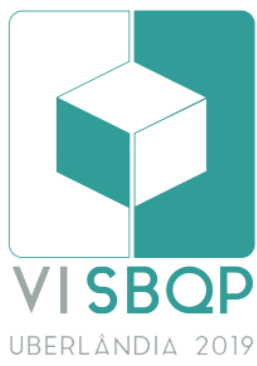

\title{
A IMATERIALIDADE PALAFÍTICA E AS ESTRATÉGIAS BIOCLIMÁTICAS PARA VILA DE PARICATUBA-AM
}

\author{
SOARES COSTA, Diana \\ UFAM, e-mail: arqdianasoares@hotmail.com \\ DE BRITTO LEITE, Maria de Jesus \\ UFPE, e-mail: jubleite@uol.com.br
}

\begin{abstract}
RESUMO
As palafitas, erguidas no entorno dos rios, lagos e igarapés, são habitações tradicionais da cultura ribeirinha cuja arquitetura pressupõe um diálogo com o ciclo das águas. É comum entre as habitações do Amazonas, sendo em geral construídas às margens dos rios, onde as inundações sazonais causam prejuízos para a população e o estado. O estudo propõe analisar a arquitetura vernacular do tipo palafita, definir estratégias bioclimáticas, investigar tecnologias e materiais sustentáveis para projetos arquitetônicos de edificações, na vila de Paricatuba, Iranduba/AM. O trabalho foi realizado através da pesquisa bibliográfica de base teórica de abordagem qualitativa e quantitativa, bem como realizadas pesquisas de campo. A partir disso, definiram-se estratégias e materiais que podem ser inseridos nas edificações: iluminação natural, energia solar fotovoltaica, resfriamento evaporativo, reaproveitamento da água da chuva, separação/destinação dos resíduos sólidos, fossa biodigestor elevada, vigas de madeiraconcreto, madeiras regionais e telha cimentícia reforçadas com tecido de fibras. É grande a perspectiva do resgate da arquitetura vernácula tipo palafita como uma preservação do modo de habitar da população ribeirinha, considerando que grande parte da população local ainda guarda valores culturais e históricos.
\end{abstract}

Palavras-chave: Arquitetura bioclimática, palafita, vila de Paricatuba, tecnologias, Amazonas.

\begin{abstract}
The palafite, erected around the rivers, lakes and streams, are traditional dwellings of the riverside culture whose architecture presupposes a dialogue with the water cycle. is common among the dwellings of the Amazon, being generally built on the banks of rivers, where seasonal floods cause damage to the population and the state. The study proposes to analyze vernacular architecture of the palafite type, to define bioclimatic strategies, to investigate technologies and sustainable materials for architectural projects of buildings, in the town of Paricatuba, Iranduba / AM. The work was carried out through bibliographic research with a theoretical basis of qualitative and quantitative approach, as well as field research. From this, we defined strategies and materials that can be inserted in the buildings: natural lighting, photovoltaic solar energy, evaporative cooling, reuse of rainwater, separation / disposal of solid waste, elevated biodigestor pit, regional woods and cementitious tile reinforced with fiber fabric. The prospect of the rescue of palafite vernacular architecture is great as a preservation of the way of living of the riverside population, considering that a large part of the local population still holds cultural and historical values.
\end{abstract}

Keywords: Bioclimatic architecture, palafite, Paricatuba village, technologies, Amazonas.

\section{INTRODUÇÃO}

OLIVEIRA (2004), relata que a Amazônia não é só natureza, ela também tem uma face urbana com especificidades locais e os seus núcleos urbanos estão ligados aos rios e florestas. É nesse cenário que registramos a presença da

SOARES COSTA, D.; DE BRITTO LEITE, M. J. A Imaterialidade Palafítica e as Estratégias Bioclimáticas para Vila de Paricatuba-AM. In: SIMPÓSIO BRASILEIRO DE QUALIDADE DO PROJETO NO AMBIENTE CONSTRUÍDO, 6., 2019, Uberlândia. Anais... Uberlândia: PPGAU/FAUeD/UFU, 2019. p. 259-268. DOI https://doi.org/10.14393/sbqp19026. 
população tradicional ou ribeirinha, que ocupa as áreas inundadas ao longo dos grandes rios Amazônicos, dos quais, cerca de $400.000 \mathrm{~km}^{2}$ corresponde a

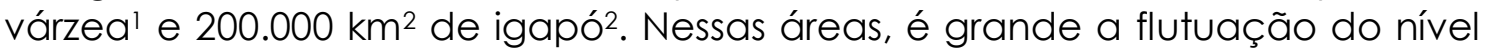
das águas dos rios, em média de 4 a 10 m, resultando em grandes inundações ao longo de suas margens (JUNK, 1980). O aumento do nível da água dos rios para além da cota média normal, faz com que as edificações construídas às suas margens estejam sujeitas a inundações causando perdas para a população.

A fim de conviver com o ciclo hidrológico, é comum que os ribeirinhos utilizem sistemas construtivos vernaculares baseados na tipologia arquitetônica de palafitas (ALENCAR; SOUSA, 2016). A palafita dialoga não somente com o ambiente físico, mas com os aspectos culturais e a vivência cotidiana dos ribeirinhos, fazendo com que esse tipo tradicional de construção, evidencie as características do modo de vida dessas populações (MENEZES; PERDIGÃO, 2013). Os autores ainda destacam que as características culturais do povo podem ser mantidas para que não se perca o significado do lugar.

A partir disso, pode-se dizer que há uma atmosfera que é própria do lugar (NORBERG-SCHULZ, 1971) e da qual fazem parte tanto as alternativas construtivas quanto os modos de conviver com a realidade ribeirinha, de se relacionar com as margens, com as adversidades da natureza e um senso de fazer parte, que caracteriza o povo e seu habitat.

O presente estudo volta-se para a compreensão de "boa ambiência" (BRITTO LEITE; GONÇALVES, 2009), para além dos estudos sobre opções arquitetônicas e urbanísticas que preservem esse modo de viver e de se relacionar com as características culturais, físicas e ambientais locais.

No entanto, apesar de possuir importância como patrimônio material e imaterial, essa arquitetura vernacular está sendo cada vez mais relacionada a situações subnormais de falta de infraestrutura básica e educação ambiental, em que predomina a ausência de coleta de lixo, saneamento básico, equipamentos públicos, espaçamento, transportes públicos, acessibilidade, segurança, além de outros serviços públicos importantes.

A partir do objeto de estudo, Vila de Paricatuba, localizada em Iranduba, cidade pequena (SCHOR; OLIVEIRA, 2011), na região metropolitana de Manaus, estado do Amazonas, o propósito é ajudar o homem a habitar, então, o objetivo concentra-se no desenvolvimento de novas propostas direcionadas para a construção/revitalização/requalificação de edificações vernaculares, de forma a promover o aumento da qualidade de vida e a melhoria da arquitetura ribeirinha a partir da [re]inserção de estratégias bioclimáticas, materiais construtivos e tecnologias como: fossa séptica biodigestora elevada, energia solar fotovoltaica, reutilização da água da chuva, bem como a implementação, entre outros.

Diante de uma solução parcial ou definitiva das inundações a partir do conceito de arquitetura vernácula, que possa ser apossado pelo arquiteto. Com isso, parte-se para a elaboração de projetos arquitetônicos e de engenharia integrados com a preservação da forma de habitar da população ribeirinha considerando que grande parte da população ainda

\footnotetext{
1 Denominação dada aos pequenos rios, na Região Norte (Amazônia). Igarapé é um termo indígena que significa "caminho de canoa" (de igara - canoa, e pé - trilha, caminho) (GUERRA \& GUERRA, 2005 p. 348).

2 Denominação regional da Amazônia para os terrenos que ficam alagados por ocasião do transbordamento dos rios, e onde existe cobertura vegetal (GUERRA \& GUERRA, 2005 p. 348).
} 
guarda valores culturais e históricos. Ressalta-se que, as estratégias bioclimáticas e tecnológicas deverão ser tema indispensável na elaboração de políticas urbanas locais de desenvolvimento das cidades Amazônicas.

\section{REVISÃO BIBLIOGRÁFICA}

Norberg-Schulz (1980), propõe que a "arquitetura representa um meio de dar ao homem uma base existencial". O ambiente influencia os seres humanos e isso implica que o propósito da arquitetura vai além das definições redutoras do funcionalismo. Para isso, também são necessárias as contribuições dos conhecimentos relativos à percepção e à simbolização humana. Quando se observa a arquitetura apenas analiticamente, há perda de caráter ambiental concreto, aquela qualidade ou valor que é objeto de identificação humana as quais fornece o sentido de uma base existencial. É nesse contexto que surge o conceito de espaço existencial, onde emerge a relação natural, originária entre o ser humano e o ambiente, visando uma compreensão concreta (física, perceptiva e social) do ambiente. Espaço, caráter, orientação, identificação, são situações diretamente relacionadas com a arquitetura e assim devem ser analisadas para manter a concretude das situações-vividas (BRITTO LEITE; GONÇALVES, 2009).

A floresta é um espaço socialmente produzido (LEFÈBVRE,1974), e as habitações tradicionais que o compõe, representam a arquitetura vernacular ao ser entendida como uma arquitetura anônima, sem interferência do arquiteto e do engenheiro, exprimindo através de uma rede de interações aspectos simbólicos do ambiente em que está inserido que determinam o caráter regional e as aspirações pessoais e coletivas de determinadas populações (MENEZES; PERDIGÃO, 2013).

De acordo com Labaki e Kowaltowski (1998, p. 63, tradução nossa) o vernáculo inclui atributos da tradição que são processos e produtos distintos, onde um modelo específico de cultura local é repetido ganhando variedade e complexidade ao longo do tempo. A arquitetura vernacular amazônica é praticada pelos ribeirinhos há muitos anos e esse conhecimento foi passado por muitas gerações a partir da cultura da população tradicional, que empregava e ainda utiliza-se dos conceitos de arquitetura bioclimática.

Os percursores da arquitetura bioclimática, os arquitetos Olgyay, destacam-se pelos trabalhos "Design with Climate" e "Architecture and Climate" por serem os criadores dos conceitos de "bioclimatismo", bem como ressalta-se a importância do arquiteto Severiano Mario Porto "o arquiteto da floresta", para o Amazonas.

Porém, tem sido comum, principalmente com a ação antrópica e o aumento na urbanização das cidades de Manaus e do interior, a desconsideração das condições ambientais, desconsiderando as especificidades e a importância da arquitetura em trabalhar de forma harmônica com a natureza.

As palafitas são consideradas ecológicas, tanto pela escolha dos materiais quanto pelas técnicas construtivas empregadas. Então, é possível que, das práticas arquitetônicas tradicionais, baseadas no conhecimento tradicional da habitação possa derivar em lições para o desenvolvimento de novos materiais de construção ecologicamente corretos, culturalmente aceitáveis e acessíveis (DE PAULA; TENÓRIO, 2010).

A Vila de Paricatuba, foi escolhida como objeto de estudo em virtude da facilidade de acesso para as coletas de informações; presença do patrimônio 
histórico e cultural dentro da região metropolitana de Manaus (Ruínas de Paricatuba); estar localizada às margens do rio Negro; ser uma pequena comunidade que passa a conviver com inúmeros conflitos socioambientais gerados pelo turismo.

Silva (2008, p. 90), destaca a percepção dos moradores da Vila, que possuem uma identificação de valores específicos que atribuem aos espaços que se traduzem em diversas dimensões como por exemplo, o sentimento topolífico, de apego ao lugar; a valorização ecológica quando percebem a importância dos recursos naturais e a necessidade de sua preservação; a valorização econômica dos espaços para a manutenção das atividades como a pesca, a agricultura, o extrativismo vegetal e a prestação de serviços, com destaque para o turismo; e a valorização das paisagens, do patrimônio histórico-cultural e arquitetônico que se constituem recursos turísticos, possuindo valor estético tanto para os moradores quanto para os visitantes. Além disso, possuem valor social, pois determinados espaços, são locais de convivência dos diversos grupos representando espaços de socialização e lazer para os moradores.

Diante disso, entende-se a importância da relação ribeirinho-palafita-floresta que pode ser considerada o principal suporte para elaboração de projetos para a região, sendo articulada na busca de respostas arquitetônicas, pois diante de uma percepção mais detalhada, nota-se que as edificações institucionais fogem do padrão cultural e que a Vila vem sofrendo uma descaracterização das edificações regionais.

\section{METODOLOGIA}

Estrutura-se nos seguintes procedimentos: 1) pesquisa bibliográfica de abordagem conceitual qualitativa para a caracterização do clima, identificação de tecnologias e materiais sustentáveis; 2) levantamento no campo, de informações sobre o modo de vida e das construções dos ribeirinhos; 3) organizar os dados em planilhas Excel e elaborar mapas a partir dos sistemas de coordenadas geográficas e DATUM SAD69; analisar e selecionar as soluções para a edificação ribeirinha; 4) desenvolver um estudo arquitetônico orientado pelas diretrizes bioclimáticas e culturais.

\section{RESULTADOS E DISCUSSÃO}

\subsection{Vila de Paricatuba, a cidade histórica de Iranduba-Amazonas}

Iranduba é o $11^{\circ}$ município em quantidade de habitantes (47.571 pessoas) dos 62 municípios do estado do Amazonas (IBGE 2018). Segundo o SNIS ${ }^{3}$ apenas 35.000 são atendidos com abastecimento de água, bem como não existe atendimento por Estação de Tratamento de Água - ETA, esgoto sanitário e coleta e a separação dos resíduos sólidos.

Localizada a vinte quilômetros da cidade de Manaus, a Vila de Paricatuba é banhada pelo Rio Negro e seu acesso pode ser feito por via fluvial ou terrestre, este último por meio do ramal de Paricatuba, com $10 \mathrm{~km}$ de extensão (Figura 1).

\footnotetext{
${ }^{3}$ Sistema Nacional de Informações sobre Saneamento - SNIS
} 


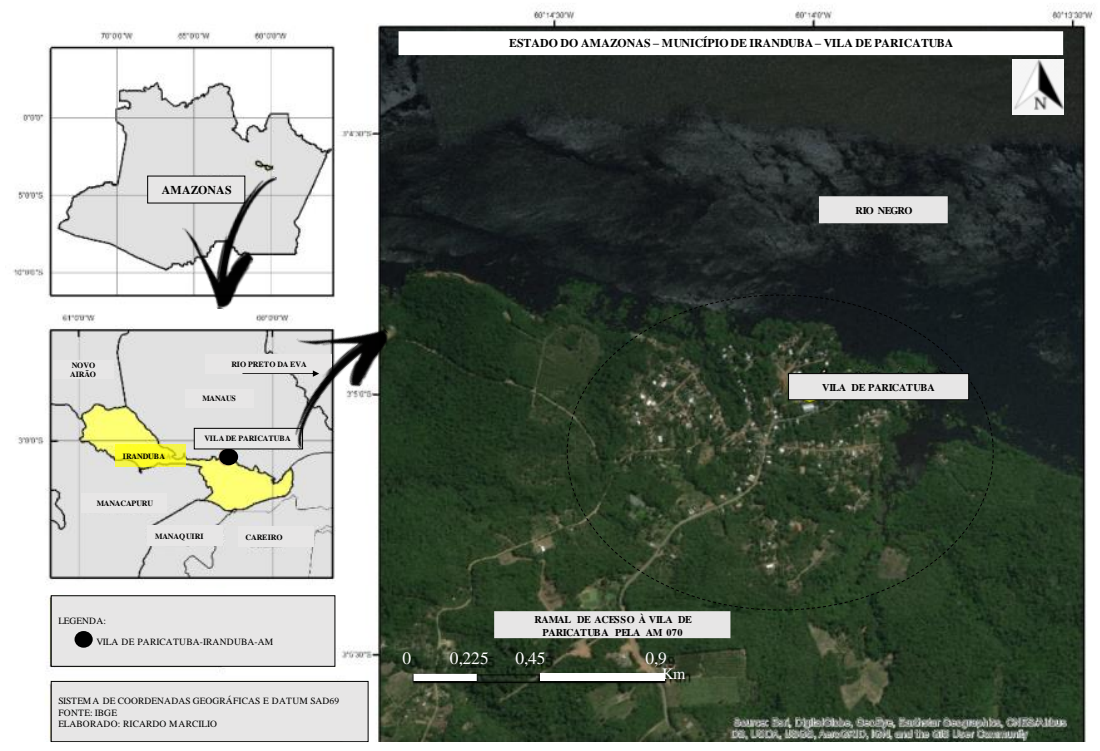

Figura 1 - Localização da Vila de Paricatuba no Estado do Amazonas Fonte: Autor (2019)

A história da Vila Paricatuba inicia-se com a construção do prédio Belisário Penna, que deveria ser uma hospedaria para imigrantes em 1898, auspiciada pelo governo, onde muito dinheiro dos cofres públicos foi empregado. 0 prédio não serviu para esse fim, abrigou presidiários, estudantes e transformouse em um asilo-colônia para hansenianos. Hoje o prédio encontra-se em ruínas (SIMONETTI et al, 2016), que são consideradas Patrimônio Histórico Cultural Imaterial do Estado do Amazonas, por meio da Lei nº 4.260 (Figura 2).

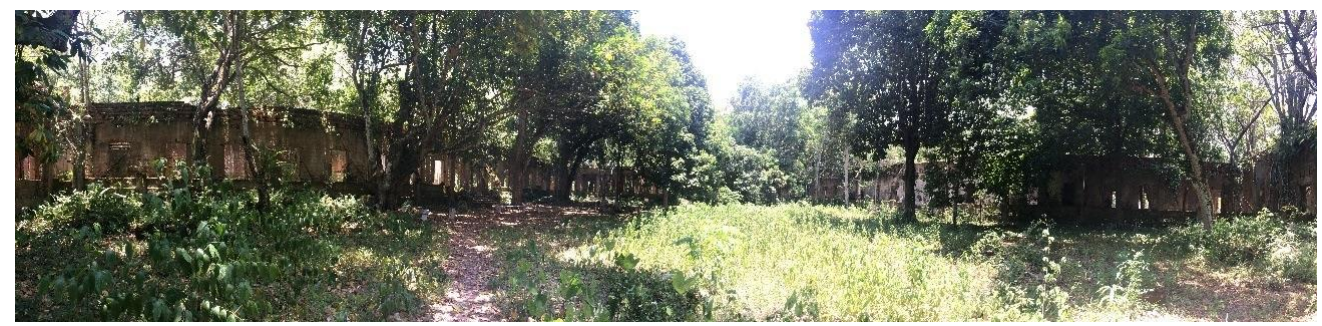

Figura 2 - Ruínas históricas da Vila de Paricatuba em Iranduba no Estado do Amazonas Fonte: Autor (2019)

\subsection{Estratégias bioclimáticas e tecnológicas para a Vila de Paricatuba}

A temperatura anual de Iranduba possui média em torno de $27^{\circ} \mathrm{C}$. Os meses com as maiores temperaturas são agosto e setembro em torno de $28^{\circ} \mathrm{C}$, enquanto janeiro e fevereiro, $26.7^{\circ} \mathrm{C}$ (Figura 3A). A umidade relativa apresenta média anual de 84 a $77 \%$. A distribuição das médias de umidade segue de perto a das chuvas, fazendo com que os menores valores ocorram na época das menores precipitações (MACEDO, 2012). A insolação anval está estimada em 1.784 horas (CARVALHO et al., 2014). Quanto às precipitações, a média anual é $2.257 \mathrm{~mm}$, com um período de maior entre dezembro a maio, inverno amazônico (Figura 3B). A estação seca, verão, ocorre no período de julho a outubro, atingindo extremos em setembro, de $40^{\circ} \mathrm{C}$.

Por escassez de dados em Iranduba, considerou-se as medições das cotas do rio Negro de Manaus por questões de proximidade, onde a variação anual das inundações é de aproximadamente $10 \mathrm{~m}$ e a cota da média de máximas anual é $27.74 \mathrm{~m}$. A enchente do rio começa no final de novembro e continua 
até o final de abril, atingindo o nível máximo, entre maio e julho (cheia). A vazante do rio começa no final de julho prosseguindo até setembro a novembro (seca) (Figura 3C). Enfatiza-se os dados do CPRM ${ }^{4}$, a partir do SAC ${ }^{5}$, que entre 27 e $28.10 \mathrm{~m}$ surgem os primeiros alagados; até $28.5 \mathrm{~m}$ cheia média; a partir de $28.50 \mathrm{~m}$ grande cheia; a partir dos $29 \mathrm{~m}$ cheia excepcional. Diante dos dados de 2009 (29.77m); 2012 (29.97m); 2013 (29.33m); 2014 (29.50m); 2015 (29.66m); 2017 (29.00m); 2019 (29.39m) percebe-se que as cotas máximas dos rios Negro, Solimões e Amazonas dos últimos anos são de cheias excepcionais.
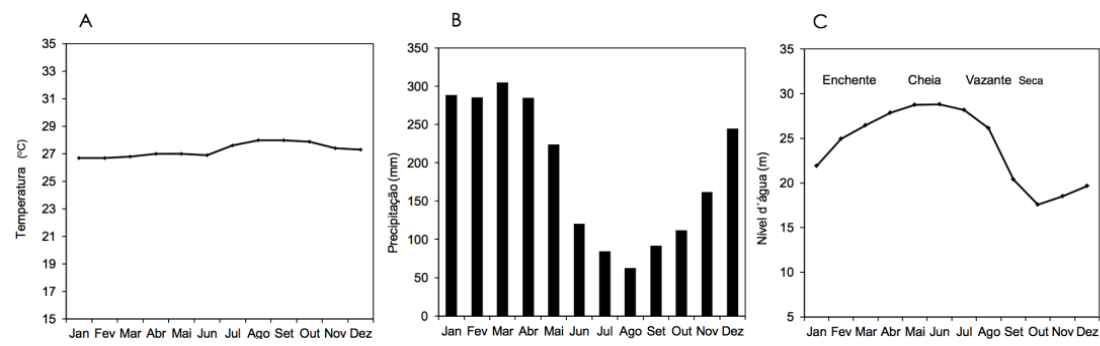

Figura 3 -Variações de temperatura em ${ }^{\circ} \mathrm{C}(\mathrm{A})$, precipitação em milímetros (B) em Iranduba no Estado do Amazonas e nível da água do rio Negro em metros em Manaus (C)

Fonte: Autor (2019)

Diante disso definiu-se as estratégias sustentáveis adequadas às edificações da Vila de Paricatuba/Iranduba, que conforme a NBR-15220-3 se enquadra na ZB8. A definição das estratégias também se basearam nos resultados dos estudos de Loureiro et al. (2002) que apresenta cartas bioclimáticas de Manaus e padrões arquitetônicos relacionados a bioclimatologia segundo LabEEE (201 1). As estratégias iluminação; ventilação; resfriamento evaporativo; energia solar fotovoltaica; reaproveitamento da água da chuva; separação/destinação dos resíduos sólidos; fossa biodigestora elevada e os materiais construtivos, estão demonstradas na Figura 3. A edificação deve estar elevada do nível do solo levando em consideração a situação de inundação, o que é peculiar à Vila de Paricatuba que possui áreas não inundáveis, porém por questões culturais elevam suas edificações.
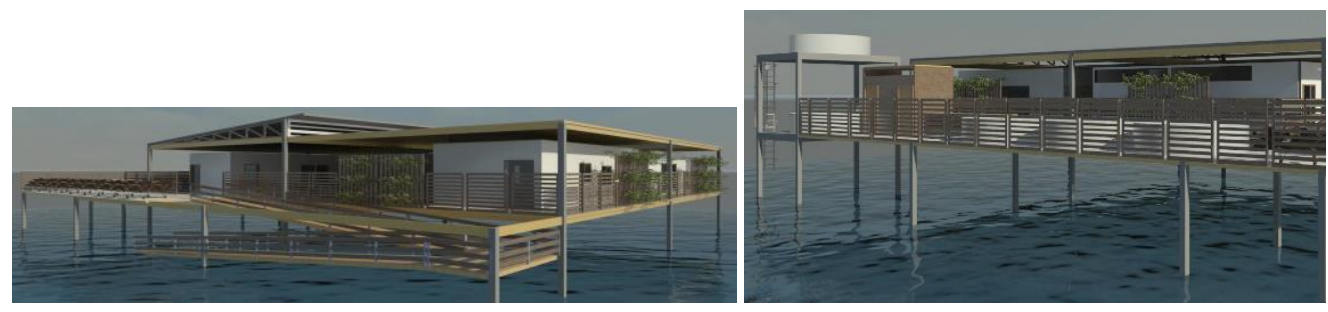

Figura 3 - Estudo de estratégias bioclimáticas, tecnológicas e materiais para edificaçōes na Vila de Paricatuba em Iranduba no Estado do Amazonas Fonte: Autor (2019)

No quesito iluminação, reduziu-se a exposição luminosa direta, optando pelo uso de iluminação indireta alcançada com o emprego de brises como barreira solar, sendo estes utilizados como suporte para vegetação trepadeira compondo uma parede verde, bem como o sombreamento $100 \%$ com o recuo de $2 \mathrm{~m}$ das paredes em todas as fachadas que facilitando a implantação. A iluminação artificial deverá ser utilizada conforme a necessidade, com zoneamento inteligente baseado na ocupação e nas

\footnotetext{
${ }^{4}$ Companhia de Pesquisas de Recursos Minerais - CPRM

${ }^{5}$ Sistema de Alerta de Cheias - SAC
} 
condições de luz do dia aplicados nos ambientes conforme seu uso. Ressaltase que a necessidade de sistemas de automação dimerizáveis como sensores de iluminação e ocupação.

A ventilação é uma estratégia de resfriamento natural do ambiente baseada na substituição do ar interno (mais quente) pelo externo (mais frio) (LabEEE, 2011). A edificação deverá possuir grandes aberturas e assim permitir a entrada da ventilação tanto na área térrea dos pilotis da palafita, como no nível elevado, telhado ventilado e utilização de lanternins, tendo como principal premissa a circulação do vento por toda área independente de sua posição. Ressalta-se a necessidade do uso de ventiladores, em conjunto ao sistema natural de resfriamento para reduzir o consumo energético da edificação e amenizar a eventual sensação de desconforto térmico por calor no verão.

Para a retirada de calor do ar pela evapotranspiração das plantas propõe-se uso de fachadas e telhados verdes. Nas fachadas verdes, técnicas simples de plantação de trepadeiras e na cobertura o telhado verde com sistema extensivo. Além disso, aplicar-se-á a estratégia das hortas e árvores frutíferas nas fachadas leste e oeste.

Na cobertura da edificação o sistema solar fotovoltaico. Essa tecnologia tem sido considerada uma das alternativas para energização de regiões isoladas como na comunidade de São Francisco de Aiucá, localizada na Reserva de Desenvolvimento Sustentável Mamirauá (RSDM) no estado do Amazonas que envolveram estudos de avaliação da sua viabilidade após seis anos de uso (MORALES et al., 2012).

A reutilização de água de chuva através de captação da água pela calha da cobertura, passando por filtragem e armazenamento em cisternas é uma ótima solução para os períodos de estiagem onde é comum a escassez de águas por causa da redução do nível de água do rio, ficando às vezes próximo as comunidades somente lâminas de água. Utilizada nos banheiros, irrigação de hortas e jardins, seu uso se justifica por não necessitar do recurso potável.

Segundo a PNRS - Política Nacional de Resíduos Sólidos (Lei n 12.305/2010), resíduos sólidos são materiais, substâncias, objetos ou bens descartados no estado sólido, semissólido ou líquido cujas particularidades tornem inviável o seu lançamento na rede pública de esgotos ou em corpos da água. Inicialmente, é recomendado que seja efetuada a coleta seletiva dos resíduos orgânicos, inorgânicos, recicláveis, não recicláveis. Com relação à destinação final dos resíduos as técnicas são: tratamento, reciclagem e disposição. No tratamento a técnica a ser considerada em virtude da localização da Vila e a falta de coleta por parte do município de Iranduba, é a reciclagem e a compostagem. É necessária a construção de abrigos para os resíduos sólidos não recicláveis e a construção de composteiras para os inorgânicos.

Quanto ao saneamento básico, a fossa séptica biodigestora elevada (OLIVEIRA et al., 2018) é de extrema importância, pois a população não é atendida com esgotamento sanitário. Por tratar-se de edificações tipo palafita, a fossa deve ser adaptada ficando no mesmo nível da edificação. Essa tecnologia visa o lançamento de água limpa no rio/igarapé e permite que o adubo líquido (efluente) que sai no final da fossa, seja utilizado na fertilização de plantas.

A escolha do material construtivo é relevante destacando-se o uso da 
madeira, um dos recursos naturais mais utilizados nas edificações vernaculares, mas que seja empregada a partir de gestão sustentável e certificada.

Com o foco na utilização de materiais regionais, a pesquisa de OLIVEIRA (2017) desenvolveu telhas cimentícias reforçadas com tecido de fibras naturais vegetais da Amazônia. Os resultados dos ensaios físico-mecânicos indicaram que as fibras utilizadas apresentam um potencial uso como reforço das placas cimentícias, formando um compósito de alta resistência, apresentando boas propriedades mecânicas e de durabilidade promissoras no desenvolvimento de peças estruturais (Figura 4). Ainda sobre compósitos, propõem-se uma construção mista com a inserção da madeira-concreto (SÁ RIBEIRO et al., 2006) que usa madeira de refugo da região e sobras de aço de construção. Os autores ressaltam que os decks compostos de madeira-concreto podem atender uma grande demanda de uso, como pontes e lajes comerciais e residenciais.

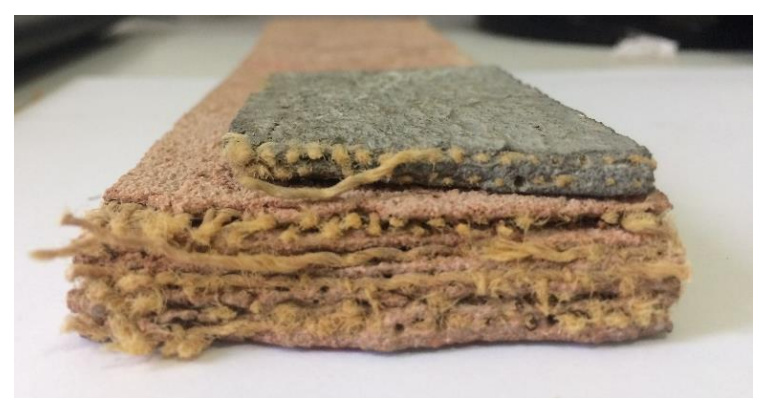

Figura 4 - Amostras do compósito formado por matriz cimentícia com fibras naturais vegetais.

Fonte: Autor (2019)

\section{CONSIDERAÇÕES FINAIS}

O modo tradicional de construção de palafitas destaca-se no ponto de vista ambiental com foco no principal fator de alteração do ambiente que são as variações sazonais do nível água dos rios e com as questões culturais dos ribeirinhos que as reconhecem como patrimônio cultural material.

O conhecimento tradicional de construção vernacular integrado as estratégias bioclimáticas e tecnológicas resulta no conceito bioclimático sendo apossado pelo arquiteto. Diante disso, na elaboração de projetos, além de proporcionar melhor qualidade de vida da população, favorecem as boas condições das edificações vernaculares o que a torna uma edificação com itens de sustentabilidade, compondo o conceito de "boa ambiência" (BRITO LEITE; GONÇALVES, 2009). Por fim, as palafitas podem ser planejadas para serem edificações referências em cultura e tecnologia para as cidades ribeirinhas, mas é necessário que os órgãos governamentais tenham uma melhor percepção da sua importância na composição da paisagem urbana/rural das cidades e as reconheçam como patrimônio arquitetônico do Amazonas.

\section{REFERÊNCIAS}

ABNT, 2005. ABNT. ASSOCIAÇÃO BRASILEIRA DE NORMAS TÉCNICAS. NBR-152203. Rio de Janeiro, 2005. 23 p.

ALENCAR, E. F.; SOUSA I. S. Tradição e mudanças no modo de habitar as várzeas dos rios Solimões e Japurá, AM. Iluminuras, Porto Alegre, p. 203-232, 2016. 
ALMEIDA, L. C. M. Habitabilidade na cidade sobre as águas: Desafios da implantação de infra-estrutura de saneamento nas palafitas do Igarapé do Quarenta - bairro Japiim - Manaus/AM. 2005. 149f. Dissertação (Mestrado em Arquitetura e Urbanismo) - UFRN, Natal.

BRITTO LEITE, M J.; GONCALVES, G. O Espaço como investigação da Arquitetura. In: IV Seminário do Projetar 2009, São Paulo: Projeto como Investigação: antologia. São Paulo: Editora Alter Market, 2009.

CARVALHO, J. S.; RUTENIO, L. C. A.; SILVA, C. A.; BASÍLIO, C. M. Avaliação de conforto térmico urbano, com base em dados de temperatura-um estudo de caso na cidade de Manaus. Scientia Amazônia, Manaus, p. 65-74, 2014.

DE PAULA A. K. M; TENÓRIO, R. Ribeirinhos: A Sustainability Assessment of Housing Typologies in the Amazon Region. International Journal of Social, Behavioral, Educational, Economic, Business and Industrial Engineering, p. 1148 $1115,2010$.

JUNK, W. J. Áreas Inundáveis - Um desafio para Limnologia. Acta Amazônica, v. 10, p. 775-795, 1980.

LABAKI, L. C.; KOWALTOWSKI, D. Bioclimatic and Vernacular Design in Urban Settlements of Brazil. Building and Environment, v. 33, n.1, p. 63-77, 1998.

LabEEE 2011 LABORATÓRIO DE EFICIÊNCIA ENERGÉTICA EM EDIFICAÇÕES (LabEEE). Desempenho Térmico de Edificações. 2011. Disponível em: < http://www.labeee.ufsc.br/ > Acesso em: 01 out 2018.

LOUREIRO, K.; CARLO, J.; LAMBERTS, R. Estudos de estratégias bioclimáticas para a cidade de Manaus. In: ENTAC IX Encontro Nacional de Tecnologia no Ambiente Construído, 2002. Foz de Iguaçu, p. 153-162.

MACEDO, A. G. S. Caracterização e variação temporal da solução do solo em argissolo amarelo com horizonte a moderado e a antrópico (terra preta de índio) no município de Iranduba-AM. 2012. Dissertação (Mestrado em Agronomia Tropical) - UFAM.

MENEZES, T. M. S.; PERDIGÃO, A. K. A. V. Modo de habitar amazônico em sistemas: aproximações com o tipo palafita. In: VI Projetar: projeto como instrumento da materialização da arquitetura: ensino, pesquisa e prática, 2013. Salvador, p. 237-254.

MORALES, L. R. V.; MOCELIN, A. R.; ZILLES, R. Estado dos sistemas fotovoltaicos domiciliares instalados em uma comunidade ribeirinha amazônica após seis anos e meio de operação. In: IV Congresso Brasileiro de Energia Solar e V Conferência Latino-Americana da ISES, 2012, São Paulo.

NORBERG-SCHULZ, C. Existence, Space \& Architecture. New York: Praeger Publishers, 1971.

OLIVEIRA, B. R.; et al. Construção do sistema de fossa séptica biodigestora adaptada para várzeas estuarinas do Rio Amazonas. Brasília, DF: Embrapa, 2018. 32 p.

OLIVEIRA, M. S. Desenvolvimento e caracterização de telhas cimentícias reforçadas com tecido de fibras vegetais da Amazônia. 2017. Dissertação (Mestrado em Engenharia Civil) - UFAM.

SILVA, G. T. Percepções sócio-espaciais e de turismo em Paricatuba IrandubaAmazonas. 2008. 115f. Dissertação (Mestrado em Ciências do Ambiente e Sustentabilidade na Amazônia), Manaus, Universidade Federal do Amazonas. 
SIMONETTI, S. R.; NASCIMENTO, E. P.; CHAVES, M. P. S. R. As representações sociais sobre turismo em comunidades do Rio Negro (Iranduba-AM). Caderno Virtual de Turismo. Rio de Janeiro, v. 16, n. 2, p. 183-199, ago. 2016.

SCHOR, T.; OLIVEIRA, J. A. Reflexões metodológicas sobre o estudo da rede urbana no Amazonas e perspectivas para a análise das cidades na Amazônia brasileira. Acta Geográfica, Boa Vista, Ed. Esp. Cidades na Amazônia Brasileira, 201 1. pp.15-30. DOI: 10.5654/actageo2011.0001.0001 